
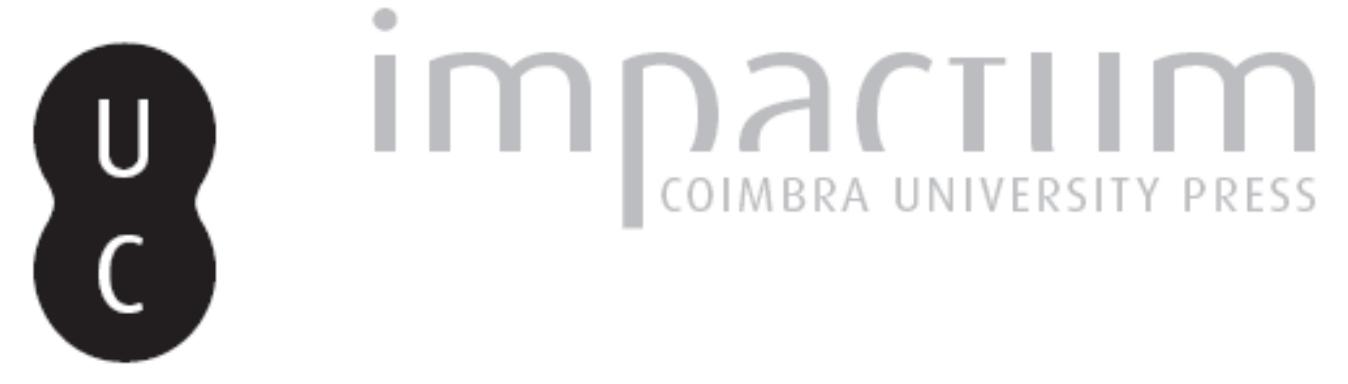

\title{
Plutarco como transmisor de Timeo: la vida de Nicias
}

\section{Autor(es): $\quad$ Candau, José M. ${ }^{a}$}

Publicado por: International Plutarch Society

URL persistente:

URl:http://hdl.handle.net/10316.2/37589

DOI:

DOI:http://dx.doi.org/10.14195/0258-655X_2_2

Accessed : $\quad$ 26-Apr-2023 14:05:36

A navegação consulta e descarregamento dos títulos inseridos nas Bibliotecas Digitais UC Digitalis, UC Pombalina e UC Impactum, pressupõem a aceitação plena e sem reservas dos Termos e Condições de Uso destas Bibliotecas Digitais, disponíveis em https://digitalis.uc.pt/pt-pt/termos.

Conforme exposto nos referidos Termos e Condições de Uso, o descarregamento de títulos de acesso restrito requer uma licença válida de autorização devendo o utilizador aceder ao(s) documento(s) a partir de um endereço de IP da instituição detentora da supramencionada licença.

Ao utilizador é apenas permitido o descarregamento para uso pessoal, pelo que o emprego do(s) título(s) descarregado(s) para outro fim, designadamente comercial, carece de autorização do respetivo autor ou editor da obra.

Na medida em que todas as obras da UC Digitalis se encontram protegidas pelo Código do Direito de Autor e Direitos Conexos e demais legislação aplicável, toda a cópia, parcial ou total, deste documento, nos casos em que é legalmente admitida, deverá conter ou fazer-se acompanhar por este aviso.

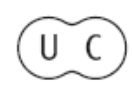




\section{Ploutarchos, n.s.}

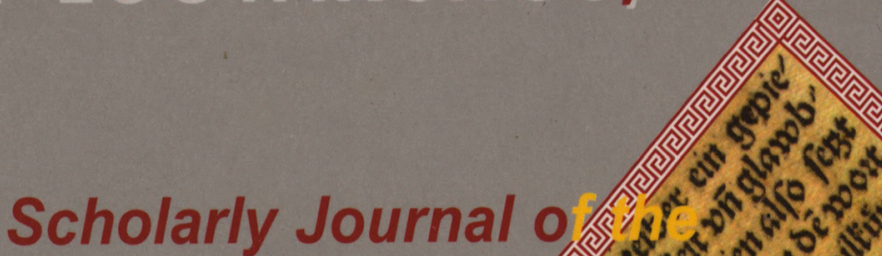

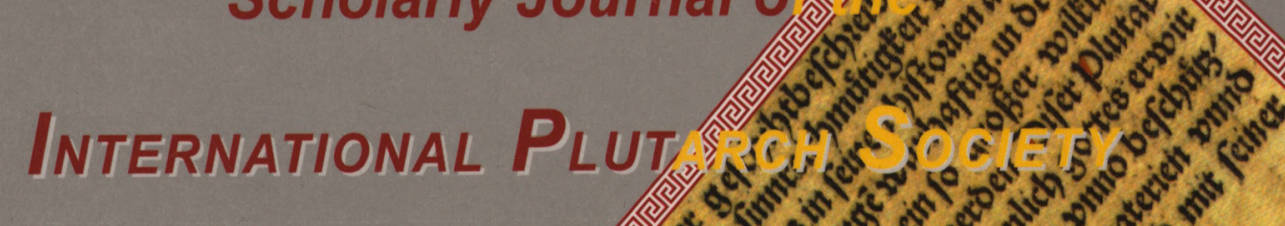

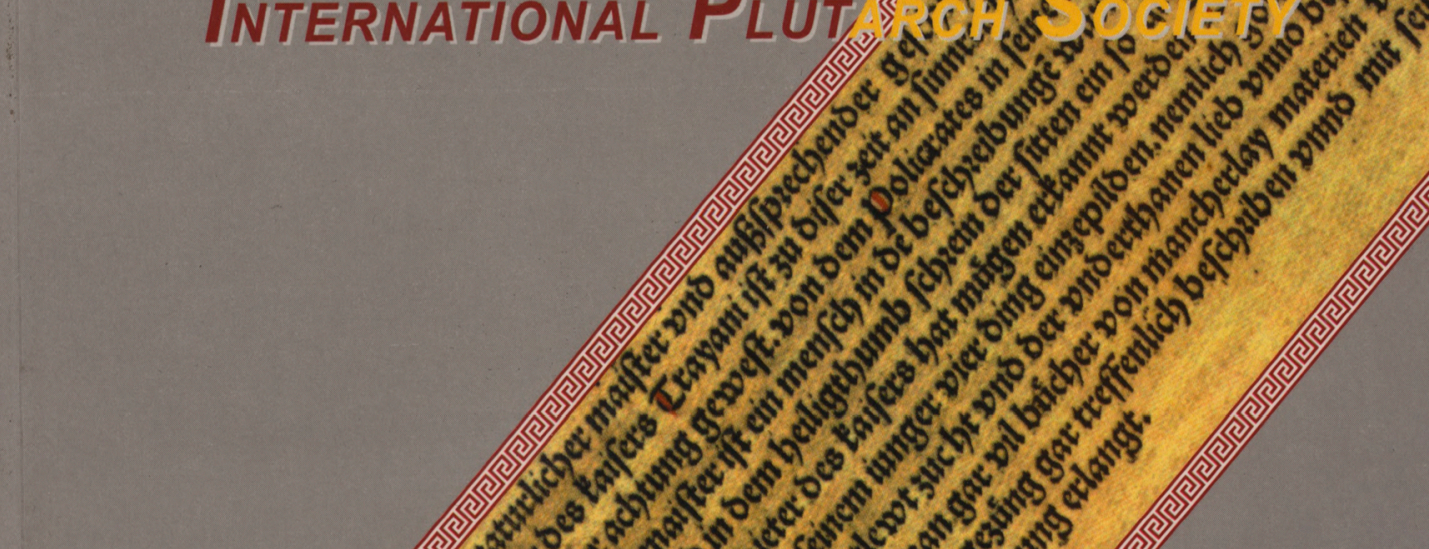




\title{
Plutarco como transmisor de Timeo. La Vida de Nicias por \\ José $\mathbf{M}^{\mathrm{a}}$ Candau \\ Universidad de Sevilla
}

\begin{abstract}
Timaeus of Tauromenium, whose work reached a wide diffusion in Hellenistic times but fell away in the Roman period, is quoted 18 times by Plutarch. The proem of the Life of Nicias is, no doubt, the more revealing of all these quotations. The proem, literally a harsh criticism of Timaeus, contains also a hidden message. In it Plutarch recognizes the influence exerted by the Hellenistic historian in the design of his biography of Nicias.
\end{abstract}

En la Grecia clásica la historiografía no fue tanto una disciplina cuanto un género literario. Ciertamente se trata de un género peculiar, pues la atención a los hechos y el imperativo de ofrecer un relato ceñido a sucesos efectivamente ocurridos es la nota que, de acuerdo con la preceptiva griega, individualiza a la obra histórica frente a otro tipo de composiciones. Pero el énfasis en la objetividad, en el carácter neutro y austero de la exposición histórica no debe inducir a engaño. Se ha afirmado que en Tucí- dides, la figura emblema de quienes presentan la historiografía griega como una actividad dominada por la imparcialidad y el factualismo, la objetividad no es un principio sino más bien una actitud de autor, un procedimiento través del cual el historiador se presenta a sí mismo y que, por tanto, viene a marcar la manera de relacionarse no con su materia, sino con sus lectores ${ }^{1}$. Por otra parte, las corrientes literarias hegemónicas a lo largo de la antigüedad grecorromana han dejado una huella clara en la producción de los sucesivos historiadores. Si las complejidades de la expre-

La génesis de esta idea en la literatura moderna sobre Tucídides la comenta W. R. ConNor, Thucydides, Princeton, 1985, p. 6. Respecto a la visión según la cual la historiografia austera y de corte pragmático conllevaría una garantía de veracidad mayor que las composiciones históricas más abiertas a los artificios retóricos y a los gustos populares, léanse las restricciones que a propósito de la literatura alejandrográfica formula A. Bosworth, "Arrian and the Alexander Vulgate", en Alexandre le Grande. Image et réalité. Entretiens sur l'Antiquité Classique 22, Vandoeuvres-Genève, 1976, 1-33. 
sión arcaica se reflejan en las Historias de Heródoto, Tucídides, cuya obra ha sido comparada a las composiciones de Esquilo, Sófocles y Platón, recoge los patrones estéticos de la Atenas clásica; el barroco helenístico se expresa vívidamente en determinados historiadores de los siglos IV y III a. C. como Clitarco, Duris o Timeo; y el clasicismo predominante a partir de Augusto tiene un impacto decisivo en la historiografía griega de época imperial ${ }^{2}$. Todo ello invita a extraer la siguiente conclusión: los historiadores griegos elaboraron sus composiciones bajo el dictado de unas demandas estéticas concretas, demandas que influían tanto en la elección de los contenidos como en la forma, en la presentación del material. Cuando una fuente posterior -un transmisor- aduce el testimonio de una obra historiográfica no conservada, lo que hace es extraer una afirmación del marco que le brindaba sentido y que ajustaba su significado. $\mathrm{Y}$ es preciso manejar con precaución ese dato descontextualizado, pues la imprudencia puede desembocar en graves malentendidos. Tan graves que en un dominio como el de la historiografía fragmentaria, abocado a trabajar con las citas y menciones de autores posteriores, la contextualización puede considerarse el mayor de los problemas.

Los intereses estéticos del transmisor $\mathrm{o}$, más concretamente, la falta de sintonía entre las coordenadas literarias bajo las que se ubican el transmisor por una parte y el texto transmitido por la otra constituye una previsible fuente de conflictos. Un buen ejemplo ofrecen los historiadores fragmentarios de época helenística. Las noticias y citas que nos informan sobre ellos proceden mayoritariamente de transmisores activos en época imperial. Ahora bien, en dicha época el gusto dominante responde a las exigencias del clasicismo vigente desde, aproximadamente, la ascensión de Augusto. Por contra, algunas de las más emblemáticas figuras de la historiografía helenística asumen principios compositivos propios de una estética que cabe asimilar al barroquismo perceptible en las artes plásticas de este mismo periodo. Y entre ambas directrices literarias, entre el clasicismo del transmisor y el recargamiento expresivo del autor

La presencia de los parámetros literarios de la Grecia arcaica en la composición de Heródoto ha sido subrayada en los estudios clásicos de H. FränKEL (Wege und Formen frühgriechischen Denkens, München, ${ }^{2} 1955$, pp. 62-85 y H. R. IMMERWAHR (Form and Thought in Herodotus, Atlanta, 1966, pp. 46-78). Igualmente clásico es el libro en que J. DE ROMILLY compara los principios compositivos de Tucídides con los vigentes en Píndaro, la tragedia del siglo V y Platón (Histoire et raison chez Thucydide, Paris, 1966, pp. 89-106). La penetración de las tendencias literarias helenísticas en la historiografia de la época puede ejemplificarse mediante Clitarco: véase JACOBY, "Kleitarchos 2)", RE 11.1 (1921), cols. 645-650. Para una muestra de la importancia del aticismo en la historiografia imperial véase F. Millar, A Study of Cassius Dio, Oxford, 1964, pp. 40-46. 
transmitido, existe una relación de incompatibilidad responsable de buena parte de las deformaciones en que incurren nuestros fragmentos. Si se quieren evitar los problemas que nacen de situaciones como la descrita, resulta imprescindible proceder a una depuración de las noticias que ofrecen los transmisores. El objetivo último será el de deshacer aquella estrategia en virtud de la cual un determinado texto se ve, simultáneamente, transmitido y ocultado ${ }^{3}$. Se trata de una tarea compleja y que no siempre cabe llevar a buen término, sobre todo por falta de material. En determinados casos, sin embargo, una relativa abundancia de datos permite plantear el intento. $Y$ uno de estos casos puede ser el de las relaciones entre Timeo de Tauromenio y Plutarco. Las dificultades de la empresa, siempre problemática, se verán recompensadas por el hecho de que las conclusiones esperables servirán no sólo para mejorar el conocimiento de autor transmitido (cuyos fragmentos se verán restituidos al contexto que pertenecen, el de la literatura helenística en nuestro caso), sino también al transmisor. La actitud frente a la tradición literaria anterior viene a ser una herramienta esencial en la definición que de sí mismos ofrecen los autores griegos de época imperial ${ }^{4}$. El juicio que ofrece Plutarco sobre una figura tan emblemática del gusto helenístico como Timeo, su manera de enfrentarse al material que le brindaba la obra de este historiador, ofrecerán el campo adecuado para reflexiones tocantes al perfil literario y a los planteamientos estéticos del autor de las Vidas Paralelas.

Timeo, nacido en Sicilia, vivió entre la segunda mitad del siglo IV y la primera del III. Su padre, Andrómaco, fundó Tauromenio y rigió los destinos de esta ciudad hasta que Agatocles, el caudillo siracusano, se apoderó de la misma. Posiblemente a esta circunstancia se debió el que durante largo tiempo Timeo residiese, quizás como refugiado político, en Atenas 5 . De los testimonios se deduce que la producción de Timeo y especialmente la Historia de Sicilia, su título más conocido, hacía un amplio uso de herramientas y procedimientos de composición típicos del arte helenístico. Polibio asegura que sus exposiciones estaban colmadas de "sueños, prodigios, fábulas increíbles y, en suma, de innoble superstición y una poco viril afición a lo prodigioso"6. Tal aseveración asimila la escritura de Timeo a una corriente historiográfica contemporá-
3

4 26-29.

5 Información básica sobre Timeo de Tauromenio proporcionan R. LAQUEUR, 1936; T. S

Brown, 1950; F. Jacoby, 1955; L. Pearson, 1984; y R. Vattuone, 1991.

6

G. SCHEPENS, 1990, pp. 166-167.

Sobre esta característica de la literatura griega imperial véase T. WHITMARSH, 2001, pp.

Plb., XII 24.5 = FGrHist 566 T19. 
nea, la llamada "historiografía trágica", cuya inclinación al patetismo, a los golpes de efecto y al diseño enfático sintoniza con la tendencia a la hipérbole y a la acentuación de los contornos perceptible en abundantes realizaciones del periodo helenístico ${ }^{7}$. Algunos fragmentos de la Historia de Sicilia evidencian la presión de modelos compositivos cómico-paródicos donde la irreverencia y el estilo desacralizante eran ingredientes de primer orden ${ }^{8}$. Otros reflejan la presencia de líneas argumentales teñidas de connotaciones religiosas ${ }^{9}$. La pintura de los personajes puede haber constituido otro de los campos donde se manifestaba la propensión de Timeo a desarrollos inesperados y a combinaciones inéditas o sorprendentes. Su retrato del político siracusano Agatocles, según denuncian sendos fragmentos transmitidos por Polibio y Diodoro, era una imagen compleja hasta la incoherencia, pues en ella gestas políticas y militares admirables convivían con una índole personal despreciable y con episodios biográficos delatores de una profunda vileza ${ }^{10}$. En realidad, de ambos fragmentos cabe deducir que el Agatocles de Timeo estaba modelado de acuerdo con los parámetros propios del llamado "retrato paradójico". Tal fue el nombre utilizado por La Penna para designar una fórmula retratística vigente al menos desde Teopompo ${ }^{11}$. El retrato paradójico es aquel que atribuye rasgos antagónicos a un mismo sujeto o en el que un individuo despliega conductas no predecibles a partir de su conformación sicológica y moral. Se trata, pues, de un procedimiento plenamente concorde con el gusto por la antítesis y por los trazos discrepantes observable en otros dominios de la Historia de Sicilia.

Si los contrastes de contenido debieron abundar en la obra de Timeo, en el plano formal los artificios de dicción y las filigranas verbales parecen haber informado de manera decisiva el perfil literario de la composición. Diversos testimonios apuntan su fuerte retoricismo y su tendencia a la expresión recargada y pomposa ${ }^{12}$; cabe destacar el anó-

Una de las mejores exposiciones sobre la historiografia trágica continúa siendo la de $\mathrm{F}$. W. Walbank, "Tragic History. A Reconsideration", BICS, 2 (1955) 4-14. Para una somera exposición del problema con bibliografia actualizada véase F. LANDUCCI GATTINONI, Duride di Samo, Roma, 1997. pp. 51-55.

8 Véase FGrHist 566 FF 124, 152 y 156 con el comentario de R. VATTUONE, pp. 34-39 y 194-197.

Véase FGrHist F119b y el comentario de R. Vattuone, pp. 99-111.

10 Plb., XII 15.1-8 = FGrHist 566 F124b; D. S., XXI $17=$ FGrHist 566 124d.

11 A. LA PENNA, "Il ritratto paradossale da Silla a Petronio", RFIC 104 (1976), 270-93.

12 Cf. FGrHist 566 T19; TT20-23. 
nimo De lo sublime, que ejemplifica los excesos estilísticos de Timeo de la siguiente manera: tras exponer determinado desmán perpetrado por Agatocles, el historiador añadía el siguiente comentario: "¿quién hubiera sido capaz de ello, sino alguien con prostitutas, y no niñas, en los ojos?"13. Otro de los rasgos que singularizaban la Historia de Sicilia era un fuerte componente polémico, plasmado en pasajes sumamente agresivos. La agresividad crítica, la acritud con que Timeo disertaba sobre personajes históricos o descalificaba la obra de otros historiadores, es quizás la afirmación más recurrente en los testimonios ${ }^{14}$. Por su aspereza y su virulencia tales críticas debieron representar una contribución no desdeñable a ese tono subido, barroco, rayano a veces en la caricatura, característico de Timeo. Resultan significativos, a este respecto, los términos en que planteaba el historiador sus comentarios y observaciones sobre figuras señeras de la política y la cultura griegas: Demócares, el sobrino de Demóstenes, conocido orador, político y filósofo activo en la segunda mitad del siglo IV, había prostituido, según Timeo, las partes altas de su cuerpo, por lo cual no era digno de soplar sobre el fuego sagrado (F35); también había prostituido determinadas partes de su cuerpo, esta vez las traseras, el siracusano Agatocles (F124b), quien además era tachado de perjuro (F121), criminal sanguinario e impío (F123a), cobarde y afeminado (F124d); y Aristóteles era un sofista pedante, impúdico, detestable y dominado por la afición a comer (F156), una afición posiblemente compartida con Homero (F152). Con semejantes credenciales, no sorprende el rumbo por el que discurrió, ya en época posterior, la fortuna literaria de Timeo. Todavía Cicerón, que ve en él un ejemplo de dicción asiánica, alaba su erudición, su riqueza intelectual y la elegancia de su estilo ${ }^{15}$. Pero unos años más tarde, con el triunfo del clasicismo y del ideal de sencillez y pureza "áticas", aparecen opiniones mucho menos favorables. Para Dionisio de Halicarnaso la dicción de Timeo es afectada, laxa y carente de sinceridad $^{16}$; Plutarco censura sus intentos de emular a Tucídides, acreditativos de un planteamiento literario inmaduro y extemporáneo ${ }^{17}$; y el autor del anónimo Sobre lo sublime, encomia su ocasional grandeza, pero ve en él un modelo de amaneramiento y $\operatorname{artificialidad}^{18}$. Todas estas descalifica-

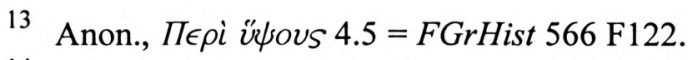

14 FGrHist 566 T1; TT11-12; T16; T18-19; T23; T27.

15 Cic., De orat. II 55-58 = FGrHist 566 T20; Brut. $325=$ FGrHist 566 T21.

16 D. H., Din. $8=$ FGrHist 566 T22.

17 Plu., Nic. $1=$ FGrHist $566 \mathrm{~T} 18$.

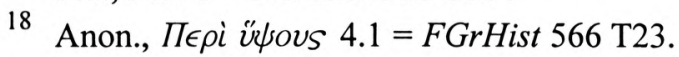


ciones son de índole formal, y probablemente a Wilamowitz y Jacoby les asiste parte de razón cuando afirman que el desprestigio de Timeo y su inclusión en las listas de autores escasamente leídos se debió a razones estilísticas, esto es, a la falta sintonía entre los procedimientos expresivos del historiador siciliano y el clasicismo augústeo ${ }^{19}$. Ciertamente, antes de que dicho movimiento triunfase Timeo gozó de amplia difusión. Pese a lo incompleto del material, Jacoby detectó su presencia en una nómina de escritores con intereses muy diversos: poetas (Calímaco, Licofrón, Apolonio de Rodas), eruditos, anticuarios y gramáticos (Eratóstenes, Demetrio de Escepsis, Varrón, Dídimo), historiadores (Polibio, Agatárquides, Posidonio, Diodoro), geógrafos (Artemidoro, PseudoEscimno), paradoxógrafos (Antígono de Caristo), etc. ${ }^{20}$. La vasta irradiación de Timeo durante el periodo helenístico no se debió -o no sólo- a la afinidad de su escritura con la sensibilidad helenística. Su Historia de Sicilia se centraba en el occidente griego, fundamentalmente Sicilia, pero también las ciudades del sur de Italia, un ámbito geográfico que en virtud de las guerras púnicas y la expansión romana atraía sobre sí la atención política de la época ${ }^{21}$. La obra incluía además el tratamiento de la historia romana, lo que, asimismo, contribuyó a dotarla de actualidad y capacidad de atracción ${ }^{22}$. Su riqueza de datos, la amplitud y variedad de su aparato erudito, es objeto de alabanzas repetidas incluso por transmisores hostiles ${ }^{23}$, y debe considerarse otro de los factores que contribuyeron a la celebridad su autor. Ahora bien, si durante el periodo helenístico Timeo fue muy leído, también de estos años datan los primeros ataques a su figura. No sabemos en qué términos se desarrollaban las críticas que le dirigieron en el siglo III Istro el Calimaqueo, autor de una Refutaciones

WILAMOWITZ, 1900, p. 8; F. JACOBY, 1955, p. 526.

20 F. JACOBY, 1957, p. 527. El predicamento del que gozó Timeo en época helenística fue indicado ya por J. GEFFCKEN (1892, pp. 177-178), que subrayó su abundante presencia en los círculos letrados de Alejandría, y es un punto en el que han coincidido distintos especialistas: véase WILAMOWITZ, 1900, p. 7-8; P. PÉDECH, Polybe. Histoires. Livre XII. Texte établi, traduit et commenté par ..., París, 1961, pp. XXXI-XXII y 144-145; F. W, Walbank, "Polemic in Polybius", JRS, 52 (1962), p. 10; G. E. LeHMANN, "Polybius und die ältere und zeitgenössische Geschichtsschreibung: Einige Bemerkungen”, en Polybe. Entretiens sur l'Antiquité classique, 20 (1973), p.161; K. MEISTER, Historische Kritik bei Polybios, Wiesbaden, 1975, pp. 52-53; Pearson, 1987, pp. 38-39 y 269-271. 
a Timeo, y, algo más tarde, Polemón el Periégeta, que escribió un Contra Ti$m e o^{24}$. Pero los juicios que vierte Polibio en el libro XII, un amplio excurso historiográfico planteado en gran medida como una diatriba contra el autor de la Historia de Sicilia, son de suma severidad y atañen tanto al fondo como a la forma. Según Polibio Timeo da muestras sobradas de incompetencia, falsedad, falta de discernimiento e ignorancia. Todos estos fallos proceden, en último extremo, de un método historiográfico equivocado y de una aproximación errónea a las tareas del historiador. Y también de aquí emanan defectos que afectan la factura formal y a la dimensión estética, pues Timeo incurre asimismo en pedantería, retoricismo, afectación y mal gusto ${ }^{25}$. La crítica que des- encadena Polibio en el libro XII no es sólo feroz, sino también injusta y parcial. La mayoría de los estudios actuales suponen que esta injusta ferocidad responde a motivos de celos y rivalidad literaria ${ }^{26}$. Resulta elocuente, a respecto, la afirmación que hace el mismo Polibio en otro lugar de su composición, cuando explica que los dos libros primeros de su obra continúan la historia de Roma en el punto donde la dejó Timeo $^{27}$. Tal afirmación debe interpretarse en el sentido de que Timeo trataba la historia romana hasta la primera guerra púnica y de que ese tratamiento le había proporcionado gran renombre ${ }^{28}$. Razones de competencia, y concretamente el deseo de desbancar a su conocido predecesor, debieron, pues, interponerse y condicionar la crítica polibia-
24

25

26

27

28

Istro: FGrHist TT 16 y 25; Polemón: T26.

Sobre la incompetencia e ignorancia de Timeo véase especialmente Plb. XII 4c.1-2; $4 \mathrm{~d} .1-4 ; 15.10-11 ; 24.5-6 ; 25.5-8 ; 25 \mathrm{e} .7 ; 25 \mathrm{~g} ; 25 \mathrm{k} .1$. Los defectos formales se hallan denunciados con claridad en aquellos pasajes que censuran los discursos de Timeo (25a 25 b; 25i.5; 26.9), pero consúltese también 8.5-6, 13.1-2 y 13.9.

Este componente de la crítica polibiana fue ya observado por estudiosos decimonónicos como C. Classen (Untersuchungen über Timaios von Tauromenion, Kiel, 1883, pp. 913) o J. GEFFCKEN (1892, pp. 180-183). Para las opiniones posteriores véase K. MeISTER, 1975, pp. 50-55; añádase K. SACKS, Polybius on the Writing of History, University of California Press, 1981, pp. 66-78; G. SCHEPENS, "Polemic and Methodology in Polybius' Book XII", en H. Verdin, G. Schepens, E. Keyser (eds.), Purposes of History. Studies in Greek Historiography from the 4th to the 2th Centuries B. C.. Proceedings of the International Colloquium Leuven, 24-26 May 1988, Lovaina, 1990, pp. 43-44; M. VERCRUYSSE, "A la recherche du mensonge et de la verité. La fonction des passages méthodologiques chez Polybe", ibid. pp. 17-38.

Plb., I 5.1; XXXIX 8.4.

Para F. JACOBY (FGrHist 566, comentario a FF59-61, p. 564) y A Momigliano, (1966 [1959], pp. 44-51), la obra de Timeo representó un punto de inflexión en la tradición historiográfica romana. 
na. Ahora bien, algunos de los reproches formulados por Polibio coinciden con los que elevan otros trasmisores. Concretamente Diodoro denuncia en un par de ocasiones la incompetencia y falsedad de Timeo ${ }^{29}$, mientras que las acusaciones de retoricismo y artificialidad reaparecen, según ya vimos, en los autores activos tras la implantación del clasicismo. Ello quiere decir dos cosas. Primero que la rivalidad literaria no basta por sí sola para explicar la severidad de Polibio frente a Timeo, ya que los mismos juicios aparecen recogidos en fuentes ajenas a tal rivalidad. Y en segundo lugar que la tesis de Wilamowitz y Jacoby -según la cual el desprestigio de Timeo se habría debido ante todo a cuestiones formales $y$, en último extremo, a la actitud hostil del clasicismo- es sólo parcialmente cierta, ya que algunas de la críticas clasicistas no hacen sino repetir las censuras de autores anteriores a este movimiento.

En la fortuna literaria de Timeo parecen entrar en juego factores diversos. Su obra obtuvo una amplia difusión durante la época helenística, pero tal difusión estuvo acompañada desde muy pronto, por refutaciones y polémicas. Razones de índole compositiva concretamente un diseño artificioso y efectista, marcado por los manierismos verbales y las estridencias de contenido- son la causa más probable de esa controvertida celebridad que acompaña a su figura casi desde el inicio. La condena emitida por los autores que comparten la preceptiva clasicista debió nutrirse de razones formales, pero también recoge argumentos registrados en fuentes anteriores. Por último, el veredicto hostil del clasicismo acarreó el desprestigio de Timeo, pero no consiguió borrar del todo la fama acumulada en torno a su nombre. Prueba de ello es el número de citas conservadas: 31 testimonios y 164 fragmentos, los seis últimos dudosos, en la edición de Jacoby. Debe recordarse que incluso una fuente adversa y compuesta bajo los parámetros del clasicismo, el anónimo De lo sublime, le reconoce una ocasional grandeza de expresión y alaba la variedad de su erudición y su inventiva. Esta complejidad, esta diversidad en los factores que determinaron la fortuna de Timeo no puede olvidarse al considerar la apreciación que de él hace Plutarco. Pues también la mirada que lanza Plutarco sobre esta figura de la historiografía helenística está llena de complejidad e incluso de contradicciones.

El autor de las Vidas Paralelas ofrece 18 citas de Timeo $^{30}$. De ellas 13 contienen informaciones que no aparecen 
en otra fuente, $\mathrm{y}$ dentro de esas 13 hay 3 que parecen ser citas textuales. ${ }^{31}$ Ello sugiere que Plutarco tenía un conocimiento directo de Timeo, un conocimiento basado en su propia lectura y no dependiente de intermediarios ${ }^{32}$. Por otra parte, de las 18 menciones 15 se refieren personajes y asuntos sicilianos, y además 14 proceden de tres biografías en los que Sicilia es o bien el escenario principal o bien un escenario de importancia mayor: las Vidas de Nicias, Timoleón y Dión. Este último dato invita a una suposición más: Plutarco utilizó una y otra vez a Timeo, lo usó de manera reiterada en composiciones que trataban de Sicilia. Si la presencia de Timeo en las mencionadas biografías no puede negarse, resulta difícil esclarecer cuál fue su rango como fuente y hasta qué punto su utilización marcó cada una de estas composiciones. Medir el impacto que produjo una obra perdida en un determinado texto constituye un ejercicio plagado siempre de escollos. Además las Vidas Paralelas son, como se sabe, obras literariamente muy elaboradas. Los temas, las anotaciones sicológicas, las observaciones morales que figuran en ellas suelen formar parte de un patrón que unifica toda la biografía, un dibujo subyacente que define al protagonista de la biografía como figura humana dotada de un contorno propio y singular. Para lograr esta conformación unificadora, Plutarco adapta, modela y combina con gran libertad el material a su disposición ${ }^{33}$, de manera que resulta muy difícil establecer con precisión cuál es el uso que hace de sus distintas fuentes. No obstante, al menos para una de las biografias sicilianas que hemos mencionado, la Vida de Nicias, poseemos datos de cuya envergadura cabe esperar conclusiones no exentas de interés.

De entre todas las citas plutarqueas de Timeo, la más sustancial es, sin

31 Informaciones inéditas: Dio $6.3 ; 14.5 ; 31.3 ; 35.6 ; 36.1 ;$ Lyc. $1.3 ; 31.7$; Tim. 4.6; 41.4; Nic. 19.5; Nic. 28.4 (referidas a la misma noticia); Nic. 1.1-3; 28.5; quaest. conv. 676d; 717c. Pueden contener palabras textuales (de acuerdo con Jacoby) Nic. 1.1-3; Lyc. 1.3; 31.7. Cf. J. GonZÁLEZ PONCE, "Metodología para una contextualización de la visión plutarquea de Timeo", en Actas del VIII Simposio Internacional de la Sociedad Española de Plutarquistas (en prensa).

32 Sobre este punto véanse U. LAFFI ("La tradizione storiografica siracusana relativa alla spedizione ateniese in Sicilia (415-13)", Kokalos, 20 (1974), p. 29) y F. Muccioli (2000, p. 294), así como la bibliografia que ambos citan.

Sobre el tema puede consultarse C.B.R. PELLING: "Plutarch adaptation of his source material”, JHS, 100 (1980), 127-40; P. A. STADTER, "Introduction", en id. (ed.), Plutarch and the Historical Tradition, London and New York 1992, 1-9; A. B. BosworTH, "History and artifice in Plutarch's Eumenes", ibid., 56-89; L. PICCIRILli, "Biografia e storia: il metodo di Plutarco", SIFC, 91 (1998), 39-60. 
duda, la contenida en el prólogo a la Vida de Nicias (FGrHist 566 T18 y F102b). Dicho prólogo constituye una crítica áspera, cerrada y extensa cuyo punto de mira es Timeo y donde se recogen los reproches que otros transmisores -Polibio por un lado, pero también los autores clasicistas- elevan contra este historiador. Debe subrayarse ante todo que en sus palabras iniciales Plutarco presenta la biografía como " $T \grave{a}$

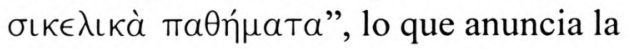
importancia que cobrará en ella la expedición a Sicilia acaudillada por Nicias. Por lo demás cabe dividir el prólogo en tres partes. La primera parte comienza con un elogio de Tucídides, autor que al describir la mencionada expedición habría alcanzado cotas insuperables de patetismo, pulcritud y destreza; de aquí que hayan de denunciarse lo intentos de Timeo por rivalizar con Tucídides mismo y con Filisto: hombre grueso, repleto de tocino siciliano: con este verso, tomado al comediógrafo Dífilo, describe Plutarco la pueril presunción en que incurre el historiador cuando se deja guiar por tan absurda rivalidad. También en el segundo paso del prólogo menciona Plutarco un nombre vinculado a la literatura cómica, esta vez el autor de mimos Jenarco: al nivel de Jenarco habría descendido Timeo llevado por su deriva literaria, una deriva que se ejemplifica mediante tres muestras: Timeo comentaba cómo habían de considerarse un aviso de la divinidad el que Nicias -cuyo nombre deriva de

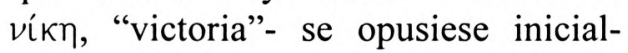

mente a la expedición; cómo, igualmente, el nombre de uno de los principales artífices de la victoria siracusana, Hermócrates, apuntaba la conexión existente entre la derrota de Atenas y la mutilación de los Hermes perpetrada en dicha ciudad en vísperas de la expedición; cómo, finalmente, Heracles ayudó a los siracusanos movido de un lado por el afán de favorecer a Core, figura vinculada a Sicilia y con la que Heracles estaba en deuda a causa de la ayuda que ésta le dispensó en su lucha con Cerbero, y de otro por enemistad a los habitantes Segesta, enemigos de los siracusanos y descendientes de los troyanos, con cuya ciudad Heracles había mantenido un conflicto. En el tercer momento de su crítica Plutarco vuelve a cargar contra las pretensiones artísticas y estilísticas de Timeo, una pretensiones informadas por mezquinos antagonismos y causantes de diversos dislates, entre otros el de cubrir de insultos a Platón y Aristóteles. El prólogo se cierra con la expresión de un propósito: de los episodios de la vida de Nicias expuestos por Tucídides y Filisto y que mediante la evocación de grandes sufrimientos descubren el carácter del personaje, sólo los esenciales serán tocadas por Plutarco; su biografía, en cambio, recogerá aspectos ignorados por la mayoría, tratados de manera esporádica o procedentes de monumentos y decretos antiguos, y ello no con objeto de reunir información carente de utilidad, sino a fin de brindar aquella que ilumina el carácter y la conducta. Debe con- 
signarse, para finalizar, que ningún otro prólogo de las Vidas Paralelas está centrado en la censura a una figura literaria, que en ningún otro la crítica a una fuente historiográfica cobra las dimensiones que aquí alcanza el ataque al autor de la Historia de Sicilia. En este sentido, el pasaje ante el que nos hallamos tiene un carácter excepcional.

Al encarar este capítulo inicial de la Vida de Nicias la crítica moderna se ha decantado hacia lo que parece ser la solución más obvia, es decir, ha supuesto que las consideraciones aquí consignadas hacen referencia al método de trabajo y a las fuentes utilizadas. Así lo entienden Flacelière y Chambry, para quienes Plutarco explicitaría en el prólogo su determinación de emplear todos los registros informativos a su alcance. Por lo demás, según ambos estudiosos, las fuentes utilizadas en la Vida de Nicias recogen la jerarquía establecida en su capítulo introductorio, pues no cabe duda de que al componer la biografía Plutarco tenía ante sí tres textos: el de Tucídides, a quien admiraba; el de Filisto, a quien estimaba; y el de Timeo, de quien desconfiaba, pero al que, pese a todo, no dejaba de prestar alguna atención. Flacelière y Chambry suponen, por tanto, que la presencia de Timeo en la Vida de Nicias es secundaria y ocasional, la que corresponde a un simple proveedor de datos cuyas afirmaciones, por otra parte, no siempre se tienen en cuenta ${ }^{34}$.

Algunos de las líneas trazadas por Flacelière y Chambry reaparecen en un par de trabajos publicados por Piccirilli en 1990 y 1993 que indagan en las fuentes de la Vida de Nicias. Piccirilli admite que el texto de Timeo debe encontrarse tras determinados pasajes de esta biografía, algo por lo demás difícil de rechazar puesto que en ella el historiador siciliano aparece mencionado cuatro veces. Ahora bien, en conjunto cabe negar que Plutarco utilizase a Timeo, pues la imagen de Nicias que ofrecen ambos autores es diferente. Efectivamente, en Diodoro el general ateniense merece una valoración positiva, y sabemos que la fuente utilizada por Diodoro para esta parte de su obra es Timeo; debe así concluirse que también en este último Nicias era objeto de una valoración favorable. En cambio la biografia de Plutarco traza un retrato esencialmente negativo de su protagonista, divergente, por tanto, del que ofrecían Diodoro y su fuente Timeo. Tal divergencia justifica la afirmación de que en la Vida de Nicias la presencia de Timeo es sólo ocasional. Piccirilli observa además que la visión negativa presente en Plutarco choca con la presentación relativamente benévola que recibe Nicias en la mayoría de la tradición, integrada por Lisias, Platón, Aristóteles, Andócides y Demóstenes ${ }^{35}$.

R. FlaceliPre - É. Chambry, 1972, pp. 132-133. También para P. A. Stadter (1988, p. 286), la cuestión de las fuentes sería el motivo básico del prólogo de la Vida de Nicias. 
Las Vidas Paralelas son composiciones de gran complejidad moral. Estudios recientes -el libro de Duff 1999 o diversas publicaciones de Stadter- han recalcado la sutileza e incluso la ambigüedad del mensaje que traslada Plutarco. Lejos de limitarse a defender las normas dominantes, el biógrafo tiende a plantear, en palabras de Duff, propuestas éticas complejas, experimentales y provocadoras $^{36}$. Ninguno de sus protagonistas está enteramente libre de defectos, y, a la inversa, personajes colmados de insuficiencias pueden, en un determinado momento, resultar admirables. Uno de estos personajes es Nicias, que da muestras sobradas de debilidad, pero es capaz también, cuando la ocasión lo requiere, de un comportamiento abnegado y heroico. Evidentemente en algunos casos pesan más las cualidades que las carencias o a la inversa, y en este sentido puede hablarse de personajes positivos o negativos, si bien con ello se incurre en una reducción simplificadora. Lo que ya no resulta admisible es utilizar esta dicotomía simplista para tratar una cuestión tan problemática como la delimitación de las fuentes. Precisamente la complejidad, el refina- miento artístico y moral de su proyecto está detrás de esa libertad con que Plutarco selecciona, combina y manipula su material. Pero si tal libertad se acepta, es ilícito afirmar que determinada Vida no puede haber utilizado determinada fuente porque las valoraciones de esta última divergen de las alcanzadas por la Vida en cuestión. Por otra parte, y desde un punto de vista más general, resulta metodológicamente incorrecto atribuir sin más los contenidos de una fuente secundaria al autor perdido que supuestamente constituye su base de información. Piccirilli incurre doblemente en esta incorrección: cuando retrotrae a Timeo el juicio favorable a Nicias de Diodoro y cuando esgrime ese juicio supuestamente favorable para negar que Plutarco tenga como fuente a Timeo. Los estudios actuales ponen de manifiesto la escasa fiabilidad inherente a tal tipo de hipótesis. Un texto derivado puede diferir de su texto origen por muchas razones, algunas banales como la abreviación, otras de mayor calado, como la intromisión de intereses políticos, literarios o morales. Cabe incluso decir que ningún texto se explica enteramente por sus

PICCIRILli, 1993, pp. IX-XII. La visión del Nicias de Plutarco como personaje esencialmente negativo predomina en la crítica actual: $c f$. A. G. Nikolaidis, "Is Plutarch Fair to Nikias?", ICS, 13.2 (1988), p. 331; T. DufF, "Plutarchean Synkrisis: comparisons and contradictions", en L. VAN DER STOCKT (ed.), 2000, p. 151; F. MuCCIOLI, 2000, p. 297; F. TITCHENER, 2000, p. 524.

36 Véase P. A. STADTER, 2000; id., "Mirroring Virtue in Plutarch's Lives", Ploutarchos, n.s. 1 (2002-2003), 89-95; T.DufF, Plutarch's Lives: Exploring Virtue and Vice, Oxford,1999; la frase citada procede de la página 9. 
fuentes ${ }^{37}$. Recurrir a una fuente perdida para elucidar las diferencias entre el Nicias de Diodoro y el de Plutarco constituye un abuso metodológico. Ambos retratos podrían tener, en realidad, una misma procedencia, pues poseemos textos que, derivando del mismo autor y tratando idéntico asunto, presentan entre sí variaciones notables.

La interpretación de FlaceliPre y Chambry plantea también dificultades. Como es sabido, en la arquitectura de las Vidas Paralelas el prólogo representa un ámbito privilegiado. Junto con la síncrisis, el prólogo constituye lo que cabe llamar capítulos marco de la composición, es decir, el espacio donde el autor formula observaciones o despliega categorías de especial relevancia para la articulación general de la obra. En principio, cada aserto presente en los capítulos marco repercute o debe repercutir, en el resto de la composición, esto es, en la parte narrativa de las biografías; y a la inversa, todo pasaje narrativo importante ilustra alguna de las afirmaciones contenidas en los capítulos marco $^{38}$. Si aplicamos todo ello a la Vida de Nicias resulta lo siguiente: al consagrar el capítulo inicial a la crítica de Timeo una de las cosas que parece

Sobre el tema en general puede consultarse G. SCHEPENS, 1990. Sobre las diferencias que pueden mediar entre un texto primario y su derivado véase J. M. CANDAU MORÓN - F. J. GonzÁlez Ponce - A. Chávez Reino - F. SÁnchez JimÉnez, “Alejandro y la historiografia helenística", Tempus, 23 (1999), p. 90.

Las ideas actuales sobre las síncrisis y los proemios de las Vidas Paralelas parten de F. FOCKE ("Synkrisis", Hermes, 58 [1923], 327-68.) y H. ERBSE ("Die Bedeutung der Synkrisis in den Parallelbiographien Plutarchs", Hermes, 84 [1956], 398-424). Las publicaciones más recientes (C. B. R. PELLING, "Synkrisis in Plutarch's Lives", en F. E. Brenk - I. Gallo [eds.], Miscellanea Plutarchea. Atti del I convegno di studi su Plutarcho, Ferrara, 1986, 83-96; P. A. STADTER [1988]; S. SwAIN , "Plutarchean Synkrisis", Eranos, 90 [1992], 101-111; D. H. J. LARMOUR "Making Parallels: Synkrisis and Plutarch's Themistocles and Camillus", ANRW II 33.6 [1992], 4154-4200; T. S. Rosenmeyer, "Beginnnings in Plutarch's Lives", en F. M. Dunn - T. Cole [eds.], Beginnings in Classical Literature [YCS, 29],1992, 205-30; J. BouloGNE "Les $\Sigma Y \Gamma$ KPI $\Sigma$ EI $\Sigma$ de Plutarque. Une rhétorique de la $\Sigma$ Y $\Gamma$ KPI $\Sigma$ I $\Sigma$ ”, en L. VAN DER STOCKT [ed.], 2000, 33-44; T. DuFF, "Plutarchean Synkrisis: comparisons and contradictions", ibid., 141-151), aceptan en general las ideas de Focke y Erbse, si bien algunos autores subrayan la diversidad de formas y funciones observables tanto en los proemios (Stadter, Rosenmeyer) como en la síncrisis (Pelling). Por otra parte las diferencias entre el moralismo simplificador dominante en la síncrisis y la mayor complejidad ética implícita en las partes narrativas de las biografias constituye un punto en el que insisten tanto Pelling como Duff, y que inducen a éste último a una propuesta innovadora respecto al papel atribuible a las síncrisis. Pese a estas diferencias, los estudios mencionados coinciden en considerar síncrisis y proemio como espacios privilegiados y portadores de un significado excepcional en el conjunto de la biografia. 
hacer Plutarco es señalar la relevancia de este autor en el diseño de la biografía. No cabe pasar por alto, desde luego, que el tono con que aquí se habla de Timeo es de recriminación sin paliativos. Pero toda crítica, cuando adquiere ciertas dimensiones, contiene una dosis de homenaje. $Y$ en todo caso existe una desproporción entre los objetivos que atribuyen Flacelière y Chambry al prólogo de la Vida de Nicias -jerarquizar sus fuentes e indicar la posición última que corresponde a Timeo en dicha jerarquía- y la prominencia que concede a la figura de este historiador tanto la extensión de la crítica como su ubicación en el ámbito excepcional del prólogo.

La literatura griega de época imperial, se ha dicho recientemente, requiere lectores que se empeñen en el proceso de descubrir significados ocultos; es una literatura de lenguaje figurado, donde las intenciones tienden a expresarse de manera encubierta; en ella las claves simuladoras y el enmascaramiento irónico constituyen ingredientes de primera importancia ${ }^{39}$. Si esto se acepta, si se admite la posibilidad de que los parámetros de ocultamiento, intenciones encubiertas y alusiones crípticas tienen vigencia también en la obra de Plutarco, cabe explicar el prólogo a la Vida de Nicias de la siguiente manera: al realzar la figura de Timeo, el biógrafo indica algo que no coincide exactamente con el sentido literal de sus palabras. El mensaje sería que en la composición de esta Vida la obra de Timeo ha constituido un motivo de inspiración importante; Plutarco reconocería, por otra parte, que el historiador siciliano incurre en excesos reprobables, razón por la cual se asumen los reproches formulados por la tradición. Se trataría, por tanto, de un mensaje matizado y en cierto sentido paradójico. Pero creo que no hay otra manera de explicar la desproporción entre rechazo literal y realce por ubicación, entre rotundidad de la descalificación y amplitud de la atención prestada, una desproporción que representa probablemente el rasgo más llamativo de este capítulo inicial. Que dicha desproporción traslada un aviso y que su mera presencia surte el efecto de entrecomillar la crítica a Timeo parece confirmado por una observación contenida en el prólogo mismo. En su final, según ya comentamos, afirma Plutarco que se ha esforzado por recoger en su biografía "lo que ha escapado a la mayoría, lo que otros han mencionado de pasada o se halla en monumentos y decretos antiguos". Ahora bien, las cualidades que con estas palabras reclama Plutarco para su biografía -erudición, inclusión de contenidos inéditos, atención a las fuentes monumentales- eran, según atestiguan diversos transmisores, rasgos prominentes de la personalidad literaria de Timeo. Polibio, Diodoro, Cicerón, y 
el anónimo Sobre lo sublime consignan como características destacadas de su obra la aportación de datos eruditos. Respecto al trabajo con las fuentes monumentales, Polibio comenta lo siguiente:

... pues quien cotejó la listas de los éforos con la de los reyes lacedemonios y la de los arcontes atenienses, la de las sacerdotisas argivas con la de los vencedores olímpicos, quien probó en las inscripciones ciudadanas referidas a tales cuestiones errores que suponen una diferencia de tres meses es Timeo. $\mathrm{Y}$ es Timeo el que ha encontrado las estelas situadas al fondo y los decretos de ciudadanía inscritos en las jambas de los templos ${ }^{40}$.

Si la hipótesis aquí defendida es cierta, el prólogo a la Vida de Nicias encerraría un mensaje en clave mediante el cual Plutarco indica de manera críptica la importancia de Timeo como elemento informador de su composición. Como suele ser norma en los estudios relativos a la historiografia fragmentaria, el carácter incompleto de nuestra documentación -en este caso la pérdida de la obra de Timeo- impide alcanzar conclusiones definitivas o inequívocas. Sin embargo determinados detalles que conciernen a la articulación general de la biografía de Plutarco permiten, al menos, construir un marco donde el mensaje comentado adquiera un sentido más pleno.

En lo tocante a la caracterización de su personaje principal, la Vida de Nicias muestra un contorno inesperado. En general la obra pinta una imagen desfavorable del general ateniense. La debilidad de Nicias, su falta de entereza ante el pueblo y los demagogos, su desmedida superstición y cierta dosis de falsedad configuran los argumentos principales de ese retrato adverso; junto a ellos se subraya también la riqueza y una prodigalidad instrumentalizada para conseguir el favor de la masa. Especialmente en los capítulos 2-6, que dibujan el perfil psicológico y moral del personaje, las notas negativas se contraponen a las apariencias positivas, dando lugar a un retrato cuya malicia alcanza en más de un pasaje cotas de farsa caricaturesca. La gravedad de Nicias, carente de severidad y adornada con prudencia, brotaba, en realidad, del miedo al pueblo y a los demagogos propio de un temperamento timorato ${ }^{41}$. Sus dispendios en festivales y celebraciones estaban dictados por la ambición política -por el deseo de hacerse con el favor de la multitud- y por una naturaleza dada a la superstición; y a propósito de esto último se consigna un malévolo dicho de Pasifonte: Nicias mantenía en su casa un adivino con quien, presuntaPlb., XII 11.1-2 = T10.

41

Nic. 2.4-5. 
mente, consultaba sobre los asuntos del estado; de hecho las consultas se referían a cuestiones privadas, especialmente a la marcha de las ricas minas de plata que eran la fuente principal de su fortu$\mathrm{na}^{42}$. Cuando se veía libre de actividades públicas, permanecía en casa sin recibir visitas; sus deudos y amigos propalaban ostentosamente el rumor de que día y noche reflexionaba sobre problemas públicos y actuaba en favor de la ciudad, y que de aquí su inaccesibili$\operatorname{dad}^{43}$. Pero el mismo Nicias que así se ufanaba rehuía las tareas políticas arriesgadas y buscaba triunfos fáciles, sin que, en su cortedad, se atreviese siquiera a enorgullecerse de estos cómodos éxitos, pues para evitar las envidias prefería atribuirlos a la fortuna $y$ al socorro divino ${ }^{44}$. Tales defectos manchan la ejecutoria del protagonista, que Plutarco describe con abundancia de pinceladas críticas y, como era de esperar, contaminan su gestión de la expedición siciliana, un episodio hegemónico en la biografia, pues domina la exposición desde su capítulo 12 hasta el final, es decir ocupa 19 de los 30 capí- tulos que componen la obra. Pese a sus fallos y carencias, todavía en el segundo año de la expedición, el 414, Nicias está al borde de la victoria y aparece a los ojos de todos como triunfador ${ }^{45}$. Las cosas comienzan a cambiar con la llegada del espartano Gilipo ese mismo año. Los reveses atenienses desembocan en una situación apurada cuando las fuerzas llegadas de Atenas al mando de Demóstenes sufren una grave derrota; al alcanzar este punto, Plutarco habla ya de la desmoralización de la tropa y de la enfermedad que se abatía sobre ella ${ }^{46}$. La gran batalla naval en el puerto de Siracusa certifica la derrota de Atenas y abre la puerta a la descripción del desastre material y el drama humano que constituye el final de la expedición y de la biografía. Y aquí, en el último tramo, se produce ese giro en la caracterización del protagonista que imprime a la obra un contorno inesperado ${ }^{47}$. En el ejército ateniense cunden el llanto y la desesperación; las perspectivas de futuro son tenebrosas; el mismo Nicias, enfermo y con las fuerzas menguadas por las privaciones, presenta el más las-

\footnotetext{
42 Nic. 4.1-2.

43 Nic. 5.

44 Nic. 6.2-4.

45 Nic. 18.7-11.

46 Nic. 22.2.
}

47 Cf. F. Titchener, "The Structure of Plutarch's Nicias", en J. A. FernÁndez Delgado F. PORDOMingo PARDO (eds.), Estudios sobre Plutarco: aspectos formales. Actas del VI Simposio español sobre Plutarco, Barcelona, 1996, p. 355 ("This biography rises and falls with Nicias' fortunes during the first chapters, peaks dramatically at the exact center of the narrattive, and then declines precipitiously, again with Nicias' fortunes.") 
timoso aspecto. Sin embargo, en medio de tantos infortunios, su figura alcanza, al menos en el plano personal, niveles insospechados de grandeza y heroísmo. Exhausto, abocado a un desastre seguro, Nicias, dice Plutarco, afrontaba penalidades, y rechazaba la desesperación no pensando en sí mismo, sino en sus tropas; éstas contemplaban los sufrimientos de su general, consideraban lo injusto su destino y concluían que ninguna ayuda divina vendría a socorrerlos. No obstante Nicias, con objeto de salvar la moral de su ejército, intentaba mediante la voz, la expresión de su rostro y la afabilidad de su trato mostrarse por encima de la desesperación ${ }^{48}$. El Nicias taimado y timorato, ese personaje cuya ambiciosa doblez dio lugar a descripciones y anécdotas de colorido burlesco, adquiere un perfil intensamente patético y despliega cualidades humanas admirables. El lector asiste además a un giro en el tono de la biografia, pues los registros cómicos perceptibles al inicio desaparecen en la parte final ante acentos decididamente trágicos.

Nada en la narración anterior anticipa la transformación de la imagen de Nicias que recogen estos últimos capítulos. Sin embargo esa transformación viene anunciada en el prólogo: recordemos que allí se habla de grandes sufrimientos que pusieron al descubierto el carácter del personaje. El prólogo también parece aludir a los diferentes regis- tros literarios tocados a lo largo de la biografia, pues si el patetismo de los capítulos finales viene indicado por la repetición de términos derivados de la raíz $\pi \alpha \theta-$, que aparecen tres veces, los momentos cómicos están reflejados en las citas y menciones de Dífilo y Jenarco. Los cambios de registros y el despliegue de cualidades inesperadas por parte del protagonista evocan procedimientos característicos de Timeo. Ciertamente Plutarco no explícita en ningún momento la conexión con Timeo. Por el contrario la evocación que comentamos es como mucho implícita, e incluso podría ser considerada una connotación casual. Pero la presencia de connotaciones casuales resulta difícilmente explicable en un lugar como el prólogo, al que se le ha atribuido un alto grado de refinamiento compositivo y densidad de significados $^{49}$. La hipótesis de que Plutarco ha utilizado en su biografia procedimientos expresivos empleados por Timeo y de que el prólogo indica de manera críptica a esa utilización explicaría además el siguiente detalle.

En el relato de Plutarco, la gran batalla naval en el puerto de Siracusa y la subsiguiente transformación de la imagen de Nicias va precedida por una serie de preliminares en los que el nombre de Heracles o derivados aparece cuatro veces. En un momento en el que Nicias, paralizado por la superstición 
ante el eclipse de luna, permanece inactivo, los jóvenes siracusanos avanzan en barcos de pescadores e injurian a los atenienses. Uno de ellos, Heraclides, es capturado por un navío ateniense, pero los siracusanos salen en su defensa y derrotan a los atenienses. Éstos reagrupan sus fuerzas y abandonan una zona donde se halla un santuario de Heracles, con lo cual los siracusanos pueden reanudar los sacrificios al héroe, una práctica que hasta entonces habían debido interrumpir. Los adivinos, después de examinar las entrañas de las víctimas, anuncian a los siracusanos que obtendrán una brillante victoria si no toman la iniciativa y tan sólo se defienden, pues Heracles había triunfado sobre sus adversarios limitándose a la defensa después de haber sido atacado ${ }^{50}$. Esta cuádruple alusión a Heracles se inserta en un pasaje de gran tensión narrativa, pues constituye la antesala inmediata al patético desenlace de la biografía. La crítica moderna ha observado que los pormenores aquí incluidos no aparecen ni en Tucídides ni en Diodoro, y por ello ha descartado que Plutarco los haya tomado de la fuentes tenidas por principales para la Vida de Nicias, Tucídides y Filisto ${ }^{51}$. En cambio Timeo aparece un firme candidato a la hora de buscar la procedencia del pasaje, ya que dos sus fragmentos registran dos de las afirmaciones que nutren el pasaje. En el fragmento 22 Polibio, consigna que, según Timeo, Heracles combatía sólo después de haber sido atacado ${ }^{52}$. Y el fragmento $102 \mathrm{~b}$ explica que, según el mismo historiador, en el conflicto entre Atenas y Siracusa Heracles ayudó a los siracusanos movido por una serie de razones relacionadas con su saga mítica. Este último fragmento ya lo hemos visto; lo transmite, como se recordará, Plutarco, y lo hace justamente en el prólogo a la Vida de Nicias. Conviene subrayar tal procedencia, porque aquí encontramos de nuevo algo más fácil de justificar como conexión calculada e indicativa que como simple coincidencia. La cuádruple referencia al nombre de Heracles y las alusiones al papel del héroe en la victoria siracusana conforman una encrucijada narrativa de gran importancia, pues preludian la derrota ateniense y anuncian los acentos trágicos que colorean toda la parte final de la biografía. Y la relación de los eventos míticos que explican la alianza entre Heracles y los siracusanos se inserta en un "capítulo marco", el prólogo, caracterizado por su alto valor programático. Ambos pasajes están marcados por la presencia explícita en un caso, implícita en otro, de Timeo. Resulta inevitable

Nic. 24.1-25.1.

51 Cf. L. Piccirilli, en M. G. Angela Bertinelli - C. Carena - M. Manfredini - L. PicCIRILli, 1993, comentario a Nic. 24.1-5; 24.6; 25.1.

52 Plb., XII 26,2. 
pensar que el uno anuncia el otro, esto es, que la mención de Heracles en el capítulo inicial anticipa la aparición del héroe en la encrucijada final de la biografia. Si ello es así surge un argumento más para considerar que la crítica desencadenada en el prólogo contiene un mensaje en clave. Aquí Plutarco reprueba a Timeo por conectar la saga de Heracles con la victoria de los siracusanos, pero en realidad esta conexión la efectúa él mismo en un lugar posterior de su composición, aquel que preludia la entrada de las tonalidades patéticas y el dominio pleno de un nuevo registro literario. De esta manera, la reprobación del prólogo indica de manera indirecta cómo el giro descrito, la coda trágica interpretada durante los últimos tramos de Vida de Nicias se inspira en Timeo.

Tal indicación no es evidente de inmediato. El pasaje del prólogo alusivo a Heracles dice así:

$Y$ [afirma Timeo] que también era lógico que Heracles ayudase a los siracusanos a causa Core, con cuya ayuda se apoderó de Cerbero, y que sintiese cólera contra los atenienses, porque iban en ayuda de los habitantes de Segesta, descendientes de los troyanos, mientras que él mismo, injuriado por Laomedonte, asoló la ciudad de Troya.

La noticia produce la impresión de que Timeo ofrecía una explicación banal, incluso absurda del resultado de la expedición ateniense; y de esta manera contribuye a la visión de Timeo como historiador alejado de la realidad, pedante, introvertido, entregado a una erudición insustancial y a una religiosidad caduca, una imagen defendida por Laqueur, Jacoby o Momigliano ${ }^{53}$. Y es difícil que un historiador de semejantes características haya podido inspirar a Plutarco o suscitar esa especie de homenaje inverso que, según nuestra hipótesis, viene a ser el prólogo a la Vida de Nicias. Sin embargo la perspectiva cambia cuando el fragmento se sitúa en las coordenadas culturales de su propia época. Lo que aquí hace Timeo es utilizar el pasado mítico de ciertas localidades griegas como aclaración o justificación de unos sucesos. Sabemos que un procedimiento usual en la diplomacia helenística era la invocación de las tradiciones locales como argumento para recabar ayuda, entablar alianzas o justificar peticiones de distinto orden ${ }^{54}$. Tal procedimiento viene ejemplificado por una inscripción hallada en Janto, en Licia, y fechada a finales del siglo III a.

R. Laqueur, 1936, cols. 1191-1192; F. JaCOBY, 1955, pp. 533-535; A. Momigliano, 1966 (1959), pp. 35-38.

54 El tema ha sido objeto de investigación en años recientes. Dos puestas al día ofrecen A. ERSKINE, 2001, pp. 163-168 y T. S. ScheER, "The Past in a Hellenistic Present: Myth and Local Tradition", en A. ERSKINE, 2003, pp. 216-231. 
C. En ella se cuenta cómo los embajadores de Citinio, una pequeña ciudad de la Dóride, recorrieron diversas comunidades de Asia Menor, entre ellas Janto, solicitando ayuda para su ciudad, que había sufrido graves daños a consecuencia de un terremoto y de una invasión. Para fundamentar su petición los embajadores de Citinio exponían diversos episodios legendarios y hacían ostentación de una compleja erudición mitológica destinada a mostrar el parentesco y las conexiones míticas existentes entre su ciudad y la de Janto ${ }^{55}$. Los representantes de Citinio, al fundamentar con estos argumentos su petición, no hacían más que recurrir a un tipo de argumentación muy empleado en la diplomacia contemporánea. Cabe así preguntar el fragmento de Timeo, con sus invocaciones al pasado mítico de las ciudades enfrentadas durante la expedición siciliana, no recoge o alude de alguna manera a una práctica habitual en las relaciones interestatales de su época. El fragmento, por otra parte, apela a Heracles y su saga mítica, con especial incidencia en los acontecimientos troyanos, para explicar el resultado de la guerra. Y también en este punto lo que aparentemente es erudición vacía puede encubrir claves literarias e ideológicas de mayor calado. En el contexto siciliano la apelación a Heracles no carece de significado político. El héroe, colonizador legendario de buena parte de la isla, fue invocado por la propaganda filodoria, que enarboló su figura como bandera de la resistencia contra las pretensiones políticas y militares mantenidas por Atenas con motivo de su expedición siciliana $Y$ en este mismo contexto las alusiones a la leyenda troyana adquieren una nueva dimensión. De acuerdo con determinadas interpretaciones modernas, las propuestas encaminadas a realzar los orígenes troyanos de las ciudades sicilianas responden a un movimiento propagandístico que intentaba devaluar los contenidos filodóricos aglutinados en torno a Heracles y dibujaba un mapa legendario de Sicilia más favorable a los intereses de Atenas $^{56}$. Cabe imaginar que los temas de esta controversia político-propagandística resuenen en el fragmento de Timeo que comentamos. En todo caso sabemos que la saga troyana desempeñó un papel muy importante en la publicística surgida alrededor de la

La inscripción se halla publicada en J. BOUSQUET. "La stPle des Kyténiens au Létôon de Xanthos", $R E G 101$ (1988), 12-53 y ha sido objeto de cita y comentario en diversas publicaciones recientes: véanse las indicaciones de A. ERSKINE, 2001, pp. 164-166 y P. DEROw, "The Arrival of Rome: from the Illyrian War to the Fall of Macedon", en A. ERSKINE, 2003, p. 57.

56 Sobre Heracles y la saga troyana como elementos propagandísticos en la historiografia y la publicística griegas centradas en Sicilia véase R. SAMmARTANO, Origenes gentium Siciliae. Ellanico, Antioco, Tucidide. Roma, 1998, 43-126 y la bibliografia que allí se cita. 
expedición de Pirro a Sicilia e Italia. Desconocemos en qué sentido utilizó el rey epirota, descendiente de Aquiles, pero también de Andrómaca, los motivos troyanos; sí parece claro que su campaña despertó fácilmente el eco de tradiciones referidos al pasado mítico de la zona ${ }^{57}$. Timeo trató la gesta de Pirro en la última parte de su Historia de Sicilia, quizás un apéndice añadido con posterioridad a su obra ${ }^{58}$. No es posible asegurar que el fragmento procedente de la Vida de Nicias recoja alusiones a la campaña siciliana de Pirro. Cabe afirmar, en cambio, con bastante verosimilitud que al mencionar el pasado troyano de las ciudades sicilianas Timeo tocaba una cuestión actual, un tema vivo, e incluso palpitante, en la propaganda política de su época.

La noticia, incluida en el prólogo a la Vida de Nicias, sobre la saga de Heracles y sobre el papel de éste en la guerra entre Atenas y Sicilia, puede muy bien encubrir un tratamiento historiográfico con más trasfondo del que deja ver Plutarco. En él Timeo pondría en juego una serie motivos ideológicos, diplomáticos y propagandísticos actuantes en la cultura política del periodo helenístico. Plutarco no sólo oculta este entramado de motivos culturales y argumentos ideológicos. Su noticia, además, tiene un tono deni- gratorio que rebaja la estatura del Timeo, presentado como historiador hueco y banal. Pero, por otra parte, aquello que se reprocha a Timeo en el prólogo -conectar la saga de Heracles con la derrota ateniense- lo lleva a cabo más adelante otro pasaje de la biografía, y lo hace de una manera que rememora los reproches formulados contra Timeo en el pasaje anterior del prólogo. La contradicción que ello implica refuerza la hipótesis según la cual el prólogo a la Vida de Nicias contiene dos mensajes: uno explícito por el que se rechaza los excesos de Timeo y se acepta el veredicto condenatorio de la crítica; otro implícito y mucho más ambiguo en el que Plutarco se distancia de la opinión mayoritaria.

El examen del prólogo a la Vida de Nicias y la hipótesis de que Plutarco insinúa en el mismo su dependencia de Timeo permiten conclusiones que afec$\tan$ en primer lugar al autor fuente $o$ transmitido, es decir a Timeo mismo. La mezcla de registros cómicos y patéticos constituye un elemento propio del historiador siciliano que recoge la Vida de Nicias. Lo mismo cabe decir del carácter del protagonista. Ya hemos visto cómo uno de los personajes mayores de la Historia de Sicilia, Agatocles, respondía a un diseño sicológicamente
57

58

Véase A. ERSKINE, 2001, pp. 157-161.

FGrHist 566 T9. Apenas sabemos nada de la parte de la obra de Timeo dedicada a Pirro (F. JACOBY, 1955, pp. 545-546), pero sobre sus posibles motivaciones y su carácter consúltese R. VATTUONE, 1991, pp. 268-273. 
complejo. Es posible además que los retratos de Timeo alcanzaran una cierta reputación, pues otro de sus personajes principales, Timoleón, es citado por Cicerón como ejemplo de ingenio historiográfico ${ }^{59}$. El Nicias de Plutarco, con esa revelación de facetas inéditas que marca el final de la biografía, parece nutrirse de los procedimientos retratísticos usados por Timeo. Los dos rasgos mencionadas, mezcla de registros y compleja factura sicológica, se integraban además en una composición donde los elementos estilísticos y formales gozan de gran preeminencia. Tal conjunto de características sugiere que los afanes estéticos y las metas puramente literarios eran ingredientes esenciales en la obra de Timeo; por contra, el didactismo político debió perder importancia o, al menos, plantearse en términos muy distintos de los que asume el planteamiento historiográfico de Tucídides o Polibio. El retroceso de la funcionalidad política sugiere, por otra parte, una escritura historiográfica mucho menos comprometida con los dirigentes de la vida pública y las facciones asociadas a ellos. En este sentido es muy posible que la oposición favorable / desfavorable constituya, como han hecho notar algunos estudios ${ }^{60}$, una herramienta reductora e inadecuada cuando se trata de reconstruir la visión que ofrecía Timeo de las figuras o acontecimientos históricos. La alusión a lemas y motivos con vigencia en las relaciones interestatales o en la propaganda diplomática -Heracles o la guerra de Troya- no debe llamar a engaño, pues Timeo pudo utilizar dichos motivos de manera lúdica o paródica, y su presencia no implica forzosamente la existencia de compromisos ideológicos o afanes políticos. Cabe así conjeturar que su Nicias era un personaje contemplado desde la distancia y donde se mezclaban cualidades y defectos, sin que el planteamiento historiográfico que informaba la composición abocase a un veredicto condenatorio o favorable, hostil o benévolo. En definitiva, la hipótesis de Timeo como fuente de la Vida de Nicias viene a confirmar, perfilar y completar lo resultados que otros estudios alcanzaron a base de analizar los fragmentos del historiador de Tauromenio.

En lo referente al transmisor, Plutarco, nuestra hipótesis indica que, pese a su mala reputación y pese a sus excesos literarios, la obra de Timeo mantenía el poder de captación suficiente para hacer presa en el autor de las Vidas Paralelas. Ya vimos cómo la reprobación de Timeo no se alimentaba sólo de motivos estilísticos y cómo en torno a su figura se aglutinan, desde el
59

60

Cic,. epist. V $12.7=$ FGrHist 566 T119c.

R. Vattuone, 1991, p. 292; K. HaEgemans, "Elissa, the First Queen of Carthage, through Timaeus' Eyes", AncSoc, 30 (2000), p. 291. 
inicio, celebridad e irradiación, pero también polémica y controversia. En época imperial, el aticismo formuló en su contra una condena inequívoca. Pero la rotundidad de este veredicto no bastó para borrar los efectos de su anterior predicamento. Se llega así a una situación en la que concurren descrédito y aprecio. El descrédito hace que las citas de Timeo no fueran citas de prestigio, lo que conduce al olvido y en último extremo a la desaparición. Por otra parte, su antigua autoridad, su predicamento como tesoro de datos sobre Sicilia y la Italia griega, mantienen su nombre en numerosas citas referidas a la historia de estas regiones e impide que su reputación quede enteramente a merced de las modas literarias. Plutarco refleja con cierta proximidad la situación descrita. La crítica sin paliativos del prólogo a la Vida de Nicias satisface formalmente las exigencias de la opinión literaria dominante. Sin embargo el biógrafo envuelve su crítica en ambigüedad, no renuncia a inspirarse en Timeo y tampoco se recata de aludir a esa inspiración, aunque de forma indirecta. Debe subrayarse además que la deuda de la Vida de Nicias frente al autor siciliano no estriba sólo en préstamos de datos o consultas eruditas. Si se acepta la hipótesis aquí defendida, lo que toma Plutarco de su fuente son los procedi- mientos literarios mismos, señaladamente aquellos que conciernen o se relacionan con el retrato psicológico del protagonista. No hay por qué cuestionar todas las afirmaciones del prólogo, y probablemente las que hacen referencia a los excesos estilísticos y retóricos responden a una actitud de auténtico repudio. Ahora bien, al tiempo que acepta el juicio "oficial" sobre Timeo, Plutarco se reserva el grado de libertad necesario para relativizar la opinión común. La ambigüedad que ello implica resulta profundamente reveladora. En varias ocasiones se ha puesto de relieve cómo las declaraciones morales de Plutarco, aparentemente de una gran ingenuidad y simpleza, encubren un pensamiento más complejo, donde las lindes entre lo aceptable y lo condenable no se distinguen con tanta facilidad ${ }^{61}$. Algo similar, pero relativo al mundo de las valoraciones literarias, se da en la Vida de Nicias con respecto a Timeo, al que al mismo tiempo se vitupera y se imita, se homenajea de manera equívoca y se condena expresamente. Estudios recientes han defendido que las Vidas Paralelas despliegan y ponen a prueba un mundo de creencias que el biógrafo comparte con sus lectores ${ }^{62}$. No es descabellado imaginar que también en los juicios literarios y gustos estéticos reinase una especie lingua franca común a ambos.

61

Sobre el tema véase, por ejemplo, D. A. Russell, “On Reading Plutarch's Lives", G\&R, 13 (1966), p. 143, así como los trabajos citados en la n. 36.

62 P. A. STADTER, 2000; M. D. SMITH, "Enkrateia: Plutarch on Self-Control and the Politics of Excess", Ploutarchos, n.s., 1, (2003/2004) 77-87. 
Plutarco, al condenar a Timeo, afirma su instalación en las coordenadas estéticas compartidas. Cuando entrecomilla y se distancia de la condena adopta un ademán típico de su personalidad literaria. Este ademán traslada al menos al menos dos comunicados: proclama su conocimiento directo, no mediado, del pasado cultural helénico y problematiza, poniéndolas a prueba, las valoraciones estéticas dominantes.

\section{Bibliografía CITADA}

Bertinelli, M. G. Angela - Carena, C. MANFREdini, M. - PicCIRILli, L.,

- Plutarco. Le Vite di Nicia e di Craso, Verona, 1993.

Brown, T. S.,

- Timaeus of Tauromenium, Berkeley Los Angeles, 1950.

ERSKINE, A.,

- Troy between Greece and Rome. Local Tradition and Imperial Power. Oxford, 2001.

- (ed.), A Companion to the Hellenistic World, Oxford, 2003

Flacelière R. - Chambry, É.,

- Plutarque. Vies. Tome VII. Cimon Lucullus / Nicias - Crassus. Texte établi et traduit par ..., París, 1972.

GeFFCKen, J.,

- Timaios' Geographie des Westens, Berlín,1892.

Momigliano, A.,

- "Atene nel III secolo e la scoperta di Roma nelle storie di Timeo di Tauromenio", en Terzo Contributo alla Storia degli Studi Classici e del Mondo Antico, Roma, 1966, 23-51 (= RSI , 7 [1959], 529-556).
JACOBY, F.,

- Die Fragmente der Griechischen Historiker. Dritter Teil b, Leiden, 1955, 526-546.

LaQueUR, R.,

- “Timaios 3", $R E 6$ A 1 (1936), 1075-1203.

MucCIOLI, F.,

- "La critica di Plutarco a Filisto e a Timeo", en L. vAN DER STOCKT, 291-307.

PEARSON, L.,

- The Greek Historians of the West. Timaeus and His Predecessors. Atlanta, 1987.

SCHEPENS, G.,

- "Jacoby's FGrHist: Problems, Methods, Prospects", in G. W. Most (ed.), Collecting Fragments - Fragmente sammeln, Göttingen 1990, 144-172.

STADTER, P. A.,

- "The Proems of Plutarch's Lives", ICS, 13.2 (1988), 273-295.

- "The Rhetoric of Virtue in Plutarch's Lives", en L. VAN DER STOCKT (ed.), 2000, 493-510.

TITCHENER, F.,

- "Practical rhetoric in Plutarch's Nicias 26.6 and Thucydides 7.86.5", en L. vaN DER STOCKT, 516-525.

VAN DER STOCKT, L. (ed.),

- Rhetorical Theory and Praxis in Plutarch. Acta of the IVth International Congress of the International Plutarch Society, Louvain - Namour, 2000.

VATTUONE, R.,

- Sapienza d'occidente. Il pensiero storico di Timeo di Tauromenio, Bolonia, 1991.

WHITMARSCH, T.,

- Greek Literaure and the Roman Empire. The Politics of Imitation, Oxford, 2001.

Wilamowitz-Moellendorf, U. von,

- "Asianismus und Atticismus", Hermes, 35 (1900), 1-52. 